\title{
El pensamiento estratégico militar en España e Iberoamérica
}

\section{Military Strategic Thought in Spain and Latin America}

\author{
José Luis Calvo Albero ${ }^{1}$ \\ Coronel del Ejército de Tierra (España)
}

Recibido: 17-04-20

Aprobado: 01-06-20

\section{Resumen}

El destacado papel representado por España en la historia no se corresponde con la importancia de su pensamiento estratégico. España estaba ya en decadencia cuando los estudios estratégicos experimentaron una gran expansión a partir del siglo XVIII. La crisis interna que se prolongó hasta el siglo XX limitó el pensamiento estratégico español a la difusión e interpretación de ideas importadas del exterior.

La América hispana siguió un camino similar. Sumida en un siglo XIX presidido por la inestabilidad tras la independencia, el pensamiento estratégico se centró allí también en la importación de ideas foráneas.

En la segunda mitad del siglo XX se produjo un renacimiento del pensamiento estratégico tanto en España como en Hispanoamérica. La incorporación de instituciones civiles al estudio de los asuntos estratégicos y la progresiva integración de esta disciplina en el marco más amplio de los estudios de seguridad permiten vislumbrar un futuro más brillante.

Palabras-clave: Pensamiento estratégico, pensamiento militar español, estrategia, literatura militar, tratadistas militares iberoamericanos.

\footnotetext{
${ }^{1}$ Coronel del Ejército de Tierra español. Profesor de estrategia y Teoría de la Guerra en la Escuela de Guerra del Ejército en Madrid (1998-2002) y en el US Army War College en Carlisle, Pennsylvania (2015-2018) actualmente es el director de la División de Coordinación y Estudios en la Secretaría General de Política de Defensa. Es autor, junto con Javier Jordán, de El nuevo rostro de la guerra (EUNSA, 2005) y, con Félix Vacas, de El conflicto de Chechenia (Publicaciones de Defensa, 2004), así como de numerosos artículos y colaboraciones en obras colectivas. Premio Defensa en 2003 y $1^{\circ}$ Premio de la Revista Ejército de Tierra en 1999, 2006 y 2010.
} 


\begin{abstract}
The outstanding role played by Spain in history does not correspond to the importance of its strategic thought. Spain was already in decline when strategic studies experienced a great expansion in the 18th century. The internal crisis that lasted until the 20th century limited Spanish strategic thinking to the dissemination and interpretation of foreign concepts.

Hispanic America followed a similar pattern. Immersed in a 19th century dominated by instability; military thought also focused on the importation of foreign ideas.

In the second half of the 20th century there was a revival of strategic thought both in Spain and in Latin America. The incorporation of civil institutions to the study of strategic matters, and the progressive integration of this discipline in the broader framework of security studies allow us to glimpse a brighter future.
\end{abstract}

Key-words: Strategic Thought, Military Thought in Spain, Strategy, Military Literature, Latin American Military Theorists.

\title{
Introducción
}

El pensamiento estratégico en España no ha estado a la altura de su importancia histórica como nación. Con esta frase podría resumirse brevemente un panorama, en general, poco satisfactorio. No es que España carezca de pensadores estratégicos, militares y civiles, ni que sus obras carezcan de mérito, pero ni se ha podido crear una escuela de pensamiento estratégico mínimamente homogénea ni alumbrar ningún pensador de prestigio universal. Pobres resultados para la que fue una de las potencias clave en la historia del mundo.

Cabe preguntarse por los motivos de este triste panorama y podrían apuntarse varios. El primero, y quizá uno de los más evidentes, es que los textos sobre pensamiento estratégico son, en su inmensa mayoría, bastante recientes. El pensamiento estratégico comienza a desarrollarse tímidamente en el Renacimiento, tras la invención de la imprenta, y vive su auténtica explosión en los siglos XVIII y, sobre todo, XIX. Y, para entonces, España se encontraba ya en franca decadencia como potencia.

El aislamiento de España de las guerras europeas a partir del final de la guerra de la independencia tuvo también mucho que ver. Aunque el siglo XIX presenció frecuentes intervenciones militares en el exterior, estas tuvieron lugar en las colonias, o fueron de poca entidad, como la guerra del Pacífico y las expediciones a México y Cochinchina, o fueron sencillamente un fugaz 
desastre, como la guerra contra Estados Unidos en 1898. El mayor esfuerzo de las fuerzas armadas se libró en el interior, con un rosario de guerras civiles y un intervencionismo militar en política, materializado mediante golpes, alzamientos y pronunciamientos diversos, que poco bien hizo a la profesionalidad de las instituciones militares españolas. Desgraciadamente, esa dinámica continuó durante gran parte del siglo XX y no favoreció en absoluto la consolidación de un pensamiento estratégico comparable al de otras potencias europeas.

Esa misma dinámica se dejó como legado a las instituciones militares de la América hispana tras los procesos de independencia. Aquejados de similares problemas sociales e institucionales, los nuevos Estados americanos terminaron por utilizar también a sus ejércitos como instrumentos de política interior, con tan nefastos resultados como en España. Aunque Iberoamérica presenció guerras interestatales de considerable entidad en el siglo XIX, el intervencionismo en política absorbió la mayor parte de las energías de las instituciones militares de la región. Pese a que aparecieron notables pensadores estratégicos, muy pocos de ellos consiguieron que su obra fuese conocida más allá de sus fronteras.

Contodo, lahistoria del pensamiento estratégico español ehispanoamericano existe, aunque permanezca prácticamente desconocida incluso para muchos profesionales de la milicia. Algunos autores, como el marqués de Santa Cruz de Marcenado, alcanzaron una fama considerable en Europa. Otros, la mayoría, se empeñaron en hacer circular por España y la América hispana las ideas que se producían en el extranjero y, en muchos casos, realizaron un encomiable esfuerzo para mejorar la profesionalidad y el conocimiento de sus compañeros de armas. Otros, una minoría, llegaron a alcanzar un notable nivel de calidad en sus obras, que desgraciadamente no fue suficiente para elevarles a la fama, en parte por el aislamiento de España e Iberoamérica de las corrientes principales de pensamiento militar y estratégico y, en parte, por la tradicional indiferencia española ante sus propios intelectuales.

En cualquier caso, ni España ni ninguna de las naciones americanas que surgió de la colonización española fueron capaces de crear una escuela coherente de pensamiento estratégico, como sí hicieron Francia, Alemania, el Reino Unido y, por supuesto, Estados Unidos. Los autores españoles e iberoamericanos se asemejan más a francotiradores aislados que a una línea de batalla bien integrada. En las últimas décadas, sin embargo, las condiciones básicas para un potencial despegue del pensamiento estratégico en España e Iberoamérica han comenzado a emerger. Las universidades han superado sus reticencias hacia los estudios estratégicos y de seguridad, mientras que las fuerzas armadas han dejado atrás un cierto antiintelectualismo que las acompañó por casi un siglo. Cada vez hay más grupos de expertos, civiles y militares que, en muchos países, comienzan a asemejarse al embrión de una escuela nacional de pensamiento estratégico. 


\section{De los orígenes al siglo XVIII}

Probablemente, el primer texto conocido escrito en territorio español sobre arte militar sea Etimologías, de San Isidoro de Sevilla, que datan de la época visigoda. Dicho texto tiene un carácter enciclopedista al intentar reunir todo el conocimiento de su tiempo en una obra. Dentro de ese conocimiento se incluye el relacionado con la milicia y la guerra, recogido en el libro 13 de los 20 que componen la obra ${ }^{2}$.

Ya en el siglo XIII, Alfonso X el Sabio, rey de Castilla, realiza una profunda reforma administrativa del Estado dotándolo de un cuerpo legal escrito. Este se materializa en los Códigos de las Siete Partidas, que siguen la tradición de los Libros de buen gobierno en los que se dan consejos al gobernante sobre cómo ejercer su autoridad y administrar el reino. La segunda de dichas partidas, dedicada al comportamiento del rey y la nobleza, incluye también temas militares, sobre todo de organización, reclutamiento y defensa de fortalezas, todos ellos aspectos críticos de la guerra medieval. También trata de las formas de hacer la guerra y de la propia naturaleza de esta, proporcionando una visión muy completa sobre la mentalidad medieval y el papel que la guerra representaba en aquella sociedad ${ }^{3}$.

En el siglo XV aparece una obra curiosa y muy ilustrativa de los inicios de la revolución en los asuntos militares que estaba ocurriendo ya en el Renacimiento. El Tratado de la perfección en el triunfo militar escrito por Alfonso de Palencia en 1459 es una alegoría de un soldado español dotado de las tradicionales virtudes castrenses que, sin embargo, no logra el éxito hasta que, visitando Italia, aprende que esas cualidades deben ir acompañadas del orden y la obediencia. Una elegante crítica a los ejércitos de los reinos españoles en aquella época, duros y valerosos, pero que no habían experimentado todavía la revolución militar por entonces en marcha en Italia, que recuperaba el modelo romano de disciplina 4 .

Es en ese momento cuando España se revela como una potencia militar de primer orden, que añade su propio modelo militar a la revolución entonces en desarrollo. El protagonista de esa hazaña será Gonzalo Fernández de Córdoba, el Gran Capitán, veterano de las guerras de Granada en las que experimentará un modelo táctico muy móvil, la importancia de la infantería equipada con

2 Julio Pérez Llamazares, Estudio crítico y literario de las obras de San Isidoro, Arzobispo de Sevilla, y la influencia de las mismas en la reforma de la disciplina y formación del clero, Editorial Crónica de León, León, 1925, p.31. Disponible en: https://bibliotecadigital.jcyl.es/es/consulta/ registro.cmd?id=5253 Consultado el 16 de marzo de 2020.

${ }^{3}$ Las Siete Partidas de Alfonso X el Sabio, PensamientoPenal. Disponible en: http://ficus.pntic. mec.es/jals0026/documentos/textos/7partidas.pdf Consultado el 17 de marzo de 2020.

${ }^{4}$ Rafael Alemany, "Dimensión humanística de una obra menor de Alfonso de Palencia: el Tratado de la perfección del triunfo militar (1459)", Anales de Literatura Española. Núm. 1, 1982, Disponible en: http://www.cervantesvirtual.com/nd/ark:/59851/bmcdv1x 8 Consultado el 18 de marzo de 2020.

Araucaria. Revista Iberoamericana de Filosofia, Politica, Humanidades y Relaciones Internacionales, año $22, \mathrm{n}^{\circ} 44$. Segundo semestre de 2020. Pp. 495-519. ISSN 1575-6823 e-ISSN 2340-2199 https://dx.doi.org/10.12795/araucaria.2020.i44.23 
primitivas armas de fuego y el valor de la fortificación de campaña. Todo esto lo pondrá en práctica contra el potente ejército francés en Italia y la victoria sobre la que entonces era la mejor caballería pesada de Europa convertirá a España en potencia militar de primer orden.

Gonzalo Fernández de Córdoba no dejará ningún tratado escrito sobre su modelo militar, pero su gesta será comentada por numerosos autores de la época. Probablemente el más conocido sea Maquiavelo que, en su Del arte de la guerra, tomará nota de la nueva modalidad de guerra. El autor florentino interpretó el modelo español como un ejemplo de retorno al modelo clásico romano: un ejército "nacional" liderado por un príncipe generoso pero enérgico, que se mostraba muy superior a los ejércitos mercenarios entonces habituales en Italia.

La idea de Maquiavelo del retorno al modelo romano va a dominar la literatura bélica y militar del siglo XVI, y también el pensamiento militar español de la época. En 1536, Diego de Salazar escribirá el Tratado de Re Militari, una versión de Del arte de la guerra adaptada a los lectores españoles. En esa adaptación, Salazar utiliza la figura de Gonzalo Fernández de Córdoba como personaje conductor del texto (en la versión de Maquiavelo, el conductor era Fabrizio Colonna, un destacado jefe militar italiano $)^{5}$.

El retorno a un modelo militar clásico era muy ilustrativo del espíritu del Renacimiento, y la obra de referencia principal para ese retorno pasó a ser De Re Militari escrita por Flavio Vegecio en el siglo V d.C. No obstante, el pensamiento militar español del siglo XVI, probablemente el momento en el que España fue más influyente desde el punto de vista estratégico, pronto se inclinó hacia los aspectos morales de la milicia. Es esta una tendencia permanente que se va a mantener en siglos posteriores y que aún se manifiesta en la actualidad.

Sancho de Londoño es probablemente el tratadista más famoso entre los que se centraron en los valores morales. En su obra Discurso sobre la forma de reducir la disciplina militar a mejor y antiguo estado, incide en la idea de regresar al modelo romano, cuya máxima expresión, y aquí puede percibirse de nuevo a Flavio Vegecio, era la disciplina. Famosa también, y de una temática similar fue el Cuerpo enfermo de la milicia española de Marcos de Isaba, publicada en $1594^{6}$.

El acento puesto en la necesidad de mejorar la disciplina en las unidades militares es un reflejo del modelo de ejército de la época en Europa, compuesto esencialmente por lo que hoy denominaríamos contratistas y que entonces se denominaban mercenarios. La dificultad para controlarlos fue en aumento,

\footnotetext{
5 Diego de Salazar, Tratado de Re Militari, Bruselas, 1590. Disponible en: http://www. bibliotecavirtualdeandalucia.es/catalogo/es/catalogo imagenes/grupo.cmd?path=151464 Consultado el 18 de marzo de 2020.

${ }^{6}$ Marcos de Isaba, Cuerpo enfermo de la milicia española, Publicaciones de Defensa, Madrid, 1991.
}

Araucaria. Revista Iberoamericana de Filosofia, Política, Humanidades y Relaciones Internacionales, año 22, $\mathrm{n}^{\circ} 44$. Segundo semestre de 2020. Pp. 495-519. ISSN 1575-6823 e-ISSN 2340-2199 https://dx.doi.org/10.12795/araucaria.2020.i44.23 
hasta llegar al desastre de la Guerra de los Treinta Años, en la que bandas de mercenarios causaron auténticos estragos en los meses que no estaban en campaña, o cuando se retrasaba la paga.

En general, se suele considerar que las tropas españolas, entre las que había numerosos nobles menores (hidalgos), eran más fiables y menos dadas al descontrol, aunque las sucesivas bancarrotas de Felipe II y la imposibilidad de que los salarios llegasen a tiempo provocaron también diversos motines entre ellas. En cualquier caso, las tropas del rey de España eran en aquel tiempo tan heterogéneas que resultaba difícil separar el comportamiento de contingentes nacionales específicos. Lo cierto es que la disciplina dejaba mucho que desear en todos los ejércitos europeos de la época y eso se reflejó de manera clara en las obras de pensamiento militar.

Aparte de los “moralistas", el siglo XVI y comienzos del XVII contemplaron la aparición de numerosos escritores militares "técnicos". En aquella época, la artillería, las fortificaciones y las técnicas de asedio constituían el máximo exponente de la tecnología militar y los libros que profundizaban en estos temas eran muy apreciados para la formación de personal especializado.

El más ilustre de los escritores técnicos fue Cristóbal Lechuga, un especialista en sitios que alcanzó el grado de sargento Mayor y fue jefe de Artillería del Ejército de Flandes. Lechuga escribió un apreciado manual técnico titulado Discurso de la Artillería y de todo lo necesario a ella, con un tratado de Fortificación y otros advenimientos ${ }^{7}$. El manual, junto con el Tratado de artillería de Diego Ufano, fue obra básica de todos los artilleros europeos hasta el final de la Guerra de los Treinta Años. Pero Lechuga también nos dejó una obra en la que fue pionero en destacar la importancia de un adecuado cuerpo de asesoramiento al general en jefe que podría asimilarse a lo que actualmente es un estado mayor. En Discurso del cargo de Maestre de Campo General ${ }^{8}$ define las funciones que dicho cargo debe desempeñar y las cualidades que deben acompañarle. También destaca como escritor técnico en el campo de la fortificación Cristóbal de Rojas y su obra Teoría y Práctica de la Fortificación publicada en 1613 .

Un tercer cuerpo de autores de temática militar en el siglo XVI español es de los historiadores, especialmente el de los cronistas oficiales, en muchas ocasiones militares que acompañaban a ejércitos y expediciones para dejar constancia oficial de sus hechos. Quizá este es el que, a largo plazo, ha dejado una huella más duradera y ha tenido mayor influencia más allá de las fronteras

${ }^{7}$ Cristóbal Lechuga, Discurso del capitan Cristoual Lechuga: en que trata de la artilleria, y de todo lo necessario à ella, con un tratado de fortificacion y otros aduertimentos.... Milán, 1611. Disponible en: http://www.cervantesvirtual.com/obra/discurso-del-capitan-cristoual-lechuga--enque-trata-de-la-artilleria-y-de-todo-lo-necessario-a-ella-con-un-tratado-de-fortificacion-y-otros-aduertimentos/ Consultado el 20 de marzo de 2020.

${ }^{8}$ Fernando Martínez Laínez, Una pica en Flandes, La epopeya del Camino Español, EDAF, Madrid, 2007. p. 182.

Araucaria. Revista Iberoamericana de Filosofia, Política, Humanidades y Relaciones Internacionales, año $22, \mathrm{n}^{\circ} 44$. Segundo semestre de 2020. Pp. 495-519. ISSN 1575-6823 e-ISSN 2340-2199 https://dx.doi.org/10.12795/araucaria.2020.i44.23 
españolas. Los historiadores militares narran acontecimientos decisivos para la historia de Europa y de la humanidad que en aquel tiempo fueron protagonizados por España. Bernal Díaz del Castillo y su Historia verdadera de la conquista de Nueva España es todavía la referencia histórica básica para comprender la conquista de México y, por extensión, la de América. Algo similar puede decirse de Francisco de Jerez y su Verdadera relación de la conquista del Perú y provincia de Cuzco llamada la Nueva Castilla.

Cabe señalar que, en la segunda mitad del siglo XVI, surge un grupo de escritores nativos americanos o mestizos que aportan una visión enormemente valiosa de la conquista, pues se trata de personas que dominan ya el castellano y se han integrado en la cultura hispánica, pero que mantienen todavía el recuerdo vivo de las civilizaciones prehispánicas. Es el caso de Titu Cusi Yupanqui y su Relación de cómo los españoles entraron en Perú y el suceso que tuvo Manco Inca en el tiempo que entre ellos vivió, del Inca Garcilaso de la Vega, probablemente el autor mestizo más conocido de esa época, con su obra Historia general del Perú10 ${ }^{10}$ o de Hernando Alvarado Tezozomóc y su Crónica mexicana.

Las guerras europeas fueron también tratadas en detalle por los historiadores militares que narraron los acontecimientos de este siglo trascendental, desde las campañas del Gran Capitán hasta las guerras en Flandes. Carlos Coloma o Bernardino Mendoza trataron las guerras en los Países Bajos ${ }^{11}$, mientras que Pedro de Salazar o Jerónimo de Torres y Aguilera se ocupan de las guerras en el Mediterráneo ${ }^{12}$. Mención especial merece Diego Hurtado de Mendoza que, a su condición de autor de obras literarias, incluso posiblemente del Lazarillo de Tormes $^{13}$, unió la de historiador con su crónica sobre la sublevación de las Alpujarras, la Guerra de Granada hecha por el rey de España don Felipe II, nuestro señor contra los Moriscos de aquel reino, sus rebeldes ${ }^{14}$.

Un último cuerpo de autores, con una relación más bien secundaria con la estrategia militar, pero que obtendrán un prestigio universal que se mantiene

9 José Rubén Romero Galván, "Los cronistas indígenas en el siglo XVII", Instituto de Investigaciones Históricas IIH, (UNAM) 2002. Disponible en: http://www.elem.mx/estgrp/datos/158 Consultado el 21 de marzo de 2020.

${ }^{10}$ M. Ruiza, T. Fernández, y E. Tamaro, "Biografía de Garcilaso El Inca". En Biografias y Vidas. La enciclopedia biográfica en línea. Barcelona, 2004. Disponible en: https://www.biografiasyvidas. com/biografia/g/garcilaso el inca.htm Consultado el 21 de marzo de 2020.

11 Álvaro Asenjo de la Hoz, "La imprenta de Marte: la guerra en los libros de la Edad Moderna", Documentos de trabajo UCM, Biblioteca Histórica; Madrid 2016/08, pp. 38-39. Disponible en: https://eprints.ucm.es/38530/1/DT2016-08.pdf Consultado el 21 de marzo de 2020.

12 Ibid. pp.39-41.

13 Blanca Berasategui, "El Lazarillo no es anónimo", elcultural.es, 5 de marzo de 2010.Disponible en: https://elcultural.com/El-Lazarillo-no-es-anonimo Consultado el 21 de marzo de 2020.

14 Diego Hurtado de Mendoza, Guerra de Granada, Cervantes virtual. Disponible en: http://www. cervantesvirtual.com/obra-visor/guerra-de-granada-hecha-por-el-rey-de-espana-don-felipe-ii-contralos-moriscos-de-aquel-reino-sus-rebeldes-historia-escrita-en-cuatro-libros--0 $/ \mathrm{html} /$ fee $8 \mathrm{dfa} 0-82 \mathrm{~b} 1$ 11df-acc7-002185ce6064 2.htm, consultado el 21 de marzo de 2020.

Araucaria. Revista Iberoamericana de Filosofia, Política, Humanidades y Relaciones Internacionales, año $22, \mathrm{n}^{\circ} 44$. Segundo semestre de 2020. Pp. 495-519. ISSN 1575-6823 e-ISSN 2340-2199 https://dx.doi.org/10.12795/araucaria.2020.i44.23 
hasta hoy en día, es el de los autores jurídicos. Sin duda, Francisco de Vitoria y los expertos de la Escuela de Salamanca son sus representantes más conocidos. Ellos se plantearon, ya en el siglo XVI, preguntas que parecen más propias de épocas muy posteriores: la legitimidad de la guerra como instrumento político o las responsabilidades legales y morales del conquistador sobre los conquistados en América. Fueron ellos quienes establecieron los cimientos del Derecho Internacional Humanitario.

En definitiva, el pensamiento estratégico y militar en los siglos XVI y principios del siglo XVII fue rico en España, en algunos aspectos como el historiográfico o el jurídico puede considerarse muy brillante, y tuvo una significativa influencia fuera de las fronteras españolas. Ciertamente, el pensamiento estratégico como tal no se desarrolló en gran medida, pero eso no fue una carencia de España, sino una consecuencia de que ese tipo de obras no se habían desarrollado todavía.

En esa época, los ejércitos pertenecían todavía al monarca, y el propio concepto de nación se encontraba en un estado muy embrionario. La guerra era un asunto práctico que dependía de factores muy específicos como la capacidad de reclutamiento y contrata, la disponibilidad de técnicos en fortificación, artillería o construcción naval, o el mantenimiento de una organización y disciplina básicas en organizaciones militares muy difíciles de controlar y que, a veces, eran más peligrosas para la propia población que para el enemigo. A esos problemas prácticos se dedicaban los tratadistas de aquel tiempo.

Ciertamente, los monarcas y sus gabinetes diseñaban y practicaban diferentes líneas de lo que hoy denominaríamos estrategia, pero la estrategia como disciplina no estaba sistematizada; y la que entonces se utilizaba era un producto del sentido común, de la experiencia práctica de reyes y nobles, y de las conversaciones y discusiones entre líderes. Solo podían deducirse trazos de estrategia de las crónicas de conflictos armados y de los libros de buen gobierno, que como El Príncipe de Maquiavelo o Theorica y pratica de la guerra de Bernardino Mendoza, trataban de educar al futuro monarca en los asuntos de Estado, entre ellos la guerra.

En la segunda mitad del siglo XVII, la decadencia de España como potencia viene acompañada de la disminución en número y calidad de las obras de pensamiento militar. Esta época resulta, sin embargo, decisiva para la transformación de la guerra como fenómeno político. El desastre de la Guerra de los Treinta Años y su colofón diplomático y legal en el Tratado de Westfalia facilitan el progreso del estado nacional moderno y, con él, se consolida la idea de ejército nacional que defendía Maquiavelo. Para evitar los desmanes de las tropas contratadas, cada nación organiza una fuerza controlada, equipada, alojada y abastecida por el Estado. Los intereses estratégicos del monarca se convierten paulatinamente en los intereses del Estado-nación que representa 
también a una clase social de burgueses dedicados a la industria y el comercio. Además, en el siglo XVIII crece el entusiasmo por la razón como guía esencial de la conducta humana y de la política de Estado; y eso abre la puerta a numerosas publicaciones sobre filosofía política, teoría del Estado y, cómo no, sobre el fenómeno de la guerra.

En España, las nuevas corrientes de pensamiento penetran especialmente tras la llegada al trono de la dinastía borbónica, tras el final de la guerra de sucesión. Pronto aparece un excelente representante de las nuevas ideas sobre la guerra, la estrategia y el uso del ejército en campaña, y el que quizás sea el escritor militar español que más renombre internacional alcanzó en su tiempo: don Álvaro de Navia y Osorio, marqués de Santa Cruz del Marcenado.

Nacido en Asturias, el marqués dedica la mayor parte de su vida a las armas. Jefe de regimiento desde su juventud, participa en algunos de los acontecimientos más importantes de la guerra de sucesión. Posteriormente, combinará esa trayectoria militar con otra diplomática que le llevará durante algunos años a Italia. Allí encontrará el ambiente y el tiempo para escribir una extensa obra sobre el arte militar de su tiempo Reflexiones militares publicadas por primera vez entre 1724 y 1727 en Turín. La obra se tradujo al francés, inglés, alemán, italiano y polaco ${ }^{15}$, y fue un auténtico libro de referencia en su tiempo, y todavía lo era a principios del siglo $\mathrm{XIX}^{16}$.

La obra de Marcenado es un compendio de casi todo lo que se sabía entonces sobre la guerra. Su mayor virtud es que utiliza un lenguaje que suele calificarse de claro y directo, y que contiene numerosas citas y ejemplos, lo que la convirtió en un buen instrumento didáctico para la formación de oficiales. Sus mayores defectos son su extensión, que se debe en gran medida a la atención y el espacio dedicado a los ejemplos, y el centrarse más en los procedimientos que en la esencia de la guerra. El marqués se esforzó en mayor medida en describir la táctica de su época que en cuestiones de índole estratégico o conceptual. No obstante, eso era lo habitual en la época y ese hábito se mantendrá hasta el siglo XIX, incluso en autores tan renombrados como Jomini. Además, Reflexiones incluye partes dedicadas precisamente a la naturaleza y a la legalidad de la guerra, o a aspectos poco tratados como la guerra en el mar o la importancia de la economía en los conflictos armados ${ }^{17}$.

El marqués de Santa Cruz no tuvo tiempo de escribir mucho más ${ }^{18}$, pues las numerosas campañas en las que participó y su temprana muerte, en 1732,

15 Pelayo Fernández García, Las Reflexiones militares del marqués de Santa Cruz de Marcenado y su influencia más allá de las fronteras nacionales, Ministerio de Defensa, Madrid, 2015, pp.71-86.

${ }^{16}$ Ibid. pp. 93-102.

17 Álvaro de Navia y Osorio, Reflexiones Militares, Secretaría General Técnica del Ministerio de Defensa, Madrid, 2004.

${ }^{18}$ Sin embargo, se suele citar otra de sus obras, que no estaba dedicada a la milicia sino a la economía del Reino, Rapsodia político económica monárquica, escrita también en la etapa italiana en la que produjo las Reflexiones (Pelayo Fernández García, Las Reflexiones militares del marqués de Santa Cruz de Marcenado y su influencia más allá de las fronteras nacionales, Ministerio de Defensa, Madrid, 2015, p.29).

Araucaria. Revista Iberoamericana de Filosofia, Politica, Humanidades y Relaciones Internacionales, año $22, \mathrm{n}^{\circ} 44$. Segundo semestre de 2020. Pp. 495-519. ISSN 1575-6823 e-ISSN 2340-2199 https://dx.doi.org/10.12795/araucaria.2020.i44.23 
durante el asedio de Orán, no le dejaron tiempo para ello. Su obra tuvo, sin embargo, una considerable influencia en la organización militar española que se prolonga incluso hasta las Reales Ordenanzas Militares de Carlos III, publicadas en 1768 .

Sin ser una obra de pensamiento estratégico, sino simplemente un conjunto oficial de reglas y normas para la organización y el funcionamiento de la institución militar, las Reales Ordenanzas merecen una mención especial por su calidad literaria. En su redacción participaron casi dos generaciones de oficiales, integrados en diversas juntas, aparte del conde de Aranda y su círculo de colaboradores. El título II de las Ordenanzas, dedicado a cuestiones morales y de mando, permaneció en vigor hasta $1978^{19}$, y algunos artículos permanecen vigentes en las actuales Ordenanzas de 2009.

Durante el siglo XVIII aparece lo que podría denominarse literatura estratégica. Se trata de obras que no solo se limitan a describir la organización y procedimientos de un ejército, sino a reflexionar sobre la propia naturaleza de la guerra y de los aspectos más conceptuales del combate como sus principios teóricos, la moral, el liderazgo o la relación entre guerra y diplomacia. En los escritos comienzan a percibirse "escuelas" nacionales como la que en Francia se desarrolla a través de autores como Folard, De Saxe o Guibert, y también comienzan a aparecer los diferentes modelos estratégicos mediante los que pueden abordarse las operaciones militares. Modelos más conservadores, centrados en una guerra limitada con un alto componente diplomático, como el propuesto por De Saxe en su Reveries o un modelo más agresivo como el propugnado por Guibert y practicado por Federico II de Prusia ${ }^{20}$.

España se mantuvo en esa época como un actor principal en la política europea, aunque con una importancia progresivamente decreciente. No surgió ningún otro autor comparable a Marcenado, y toda la institución militar entró en una profunda crisis durante el reinado de Carlos IV, motivada por la ruina económica y los desastres bélicos. Los mediocres resultados en la lucha contra la Francia revolucionaria en la Campaña de los Pirineos fueron seguidos por el desastre naval de Trafalgar y por el desastre mucho mayor de la invasión napoleónica.

\footnotetext{
${ }_{19}$ Pedro Luis Pérez Frías, "El Ejército de Carlos III", Revista Péndulo, no 18, 2007, pp.123-124. Disponible en: https://dialnet.unirioja.es/servlet/autor?codigo=819236 Consultado el 22 de marzo de 2020 .

${ }^{20}$ R.R. Palmer, "Federico el Grande, Guibert, Bulow. De las guerras dinásticas a las nacionales" en Paret, Peter, Creadores de la Estrategia Moderna, Ministerio de Defensa, Madrid, 1992, pp. 103-122. 


\section{EI siglo XIX}

En Europa, las guerras de la revolución y el Imperio francés cambiaron radicalmente el carácter de los conflictos armados. Frente a los pequeños ejércitos profesionales y guerras limitadas del siglo XVIII, se recurre a la movilización de todos los recursos de la nación para la guerra. Ejércitos de cientos de miles de combatientes se enfrentan en batallas gigantescas y en algunos países como España, Portugal y Rusia la población civil se une a las hostilidades utilizando tácticas de guerrilla.

En la explosión de sentimientos que trae consigo el nuevo nacionalismo y el Romanticismo, la guerra se expande como no lo había hecho desde la Guerra de los Treinta Años. En Francia, en particular, Napoleón pone en práctica las ideas acuñadas en el siglo anterior sobre la dispersión de los ejércitos en fracciones para la maniobra previa a la batalla y su concentración en lugar y momento oportuno para librarla. Nace un nuevo modelo de estrategia militar de nivel operacional que se va a mantener como modelo hasta finales del siglo XX.

Las campañas de Napoleón tienen dos intérpretes principales. Inicialmente, el suizo Henri Antoine de Jomini, que sirvió como general del emperador francés, es el más leído. Jomini escribe dos obras, el Tratado de la gran táctica y el Resumen del arte de la guerra, que se convertirán en libros de referencia para cualquier mando europeo hasta el final del siglo XIX. Jomini es, en realidad, un hombre del siglo XVIII que sabe describir muy bien los cambios en la táctica y en la conducción de campañas militares, pero omite los cambios trascendentales en el propio concepto de la guerra. En este segundo aspecto destaca, sin embargo, Carl von Clausewitz, un oficial y general prusiano que también sirve en las guerras napoleónicas y que escribe una obra que se publicará tras su muerte, De la guerra, que se ha mantenido hasta hoy en día como el texto fundamental de la teoría de la guerra.

En España tras la victoria en la devastadora guerra de la independencia, se produce una explosión de pensamiento militar, en consonancia con otros países europeos. Numerosos autores se lanzan a interpretar tanto las campañas de Napoleón como las campañas de la guerra de la independencia. Sin embargo, el estado de inestabilidad permanente en el país, la pérdida de las colonias norteamericanas y la concentración del pensamiento nacional en la pugna política entre liberales y conservadores no favorecerá la consolidación de una auténtica escuela de pensamiento estratégico.

Precisamente las guerras de independencia en la América hispana producirán el nacimiento de nuevos Estados y, con ellos, la tradición militar hispana se dividirá en dos, aunque en ambos casos el desarrollo del pensamiento militar se verá muy afectado por las similares características 
de ambas sociedades. El modelo político, social y económico español tendrá dificultades para adaptarse a los cambios del siglo XIX. La debilidad de la sociedad civil encarnada en la burguesía hará que los ejércitos aparezcan como una solución temporal para garantizar la estabilidad de los nuevos Estados, pero eso llevará a una tradición de intervencionismo militar en política de muy negativas consecuencias.

En España, adquieren un papel importante y cierta relevancia internacional los historiadores de la guerra de la independencia. José María Queipo de Llano, conde de Toreno, escribirá Historia del levantamiento, guerra y revolución en España, que será durante décadas la principal obra de referencia sobre la visión española del conflicto para los historiadores extranjeros. Ya a finales de siglo, el general José Gómez de Arteche escribirá la Guerra de la Independencia. Historia militar de España (1808-1814). La obra, escrita desde un punto de vista completamente militar, pretendía neutralizar la visión de la historiografía británica, muy basada en William Patrick Napier ${ }^{21}$, que era extraordinariamente despectiva hacia el papel español en el conflicto. Lo cierto es que el que se convertiría en historiador extranjero más prestigioso en estudiar nuestra guerra de la independencia (guerra peninsular en el mundo anglosajón), Charles Oman, tomó como referencia la obra de Arteche y modificó notablemente la visión sesgada de Napier $^{22}$.

Como en el resto de Europa, en España se pueden identificar dos etapas bien diferenciadas en el pensamiento militar. La primera, hasta la década de 1860-1870, está dominada por el modelo napoleónico, interpretado por Jomini. La segunda, a partir de 1870 , cambia la perspectiva hacia el modelo prusiano-alemán, después de su éxito en las guerras contra Austria y Francia en 1866 y en 1870. Clausewitz se convertirá entonces en el referente principal, aunque la influencia de Jomini y el modelo napoleónico se prolongarán hasta el siglo XX.

En la primera etapa destaca la figura del comandante Francisco Villamartín. Su obra principal, Nociones del arte militar, publicada en 1862, se convirtió en la obra española de mayor proyección internacional en el siglo XIX, principalmente por la atención que despertó en la Francia de Napoleón III $^{23}$. Villamartín fue el originador de lo más parecido a una escuela de pensamiento estratégico que haya

${ }^{21}$ Charles Frederick Napier combatió en España como teniente coronel en el ejército del Duque de Wellington y escribió Historia de la Guerra en la Península y en el Sur de Francia. 1807-1814 que fue la referencia esencial para los historiadores de la "Guerra peninsular" durante el siglo XIX. La obra era enormemente hostil hacia los ejércitos y guerrillas españolas, a los que consideraba más un estorbo que un elemento de importancia en la victoria final. (W. Napier, History of the War in the Peninsula and in the South of France from the Year 1807 to the Year 1814, Londres, 1828-1840).

22 El propio Oman agradeció a Arteche en el Prefacio de su obra la puesta a su disposición de su archivo privado, (Charles Oman, A History of the Peninsular War Vol II, Oxford Clarendon Press, 1903, Prefacio p.VII).

${ }^{23}$ Guillermo Pinto Cebrián, Ejército e historia. El pensamiento profesional militar español a través de la literatura castrense decimonónica, Ministerio de Defensa, Madrid, 2013, p.47. 
aparecido en España y, como Clausewitz y Jomini, tuvo también sus seguidores e intérpretes nacionales ${ }^{24}$.

Villamartín puede considerarse como un “jominista” tardío. Sus ideas básicas sobre operaciones son las del teórico suizo, pero su concepción de la guerra ha sido modelada por los avances tecnológicos del siglo XIX y por el desarrollo del nacionalismo. Eso hace que en algunos asuntos como la importancia del pueblo y la opinión pública en un conflicto, o la necesidad de una movilización humana e industrial completa y eficiente, gire hacia las ideas de la escuela prusiana representada por Clausewitz. En cualquier caso, el talento de Villamartín se malogrará por su temprana muerte, en 1872, a los 39 años de edad.

En la segunda etapa del siglo XIX la atención al pensamiento militar aumenta considerablemente. La Restauración trae un tiempo de cierto sosiego a la vida política, el intervencionismo militar queda temporalmente neutralizado y el esfuerzo de las instituciones militares se concentra en la modernización, atendiendo especialmente a las lecciones de la guerra franco-prusiana de 1870 . Aunque hay muchos tratadistas notables, destaca la figura del general José Almirante, uno de los autores más prolíficos de la historia del pensamiento militar en España.

Almirante es esencialmente un recopilador de ideas de otros autores ${ }^{25}$, pero su trabajo tiene una gran importancia porque documenta la evolución del pensamiento militar y estratégico en España y describe muy bien el estado de la cuestión en su época. Sus obras, Diccionario militar, etimológico, histórico, tecnológico (1869) y Bibliografía militar de España, se convierten en indispensables para cualquier estudioso de la evolución del pensamiento militar en nuestro país. Asimismo, su Reglamento para el servicio en campaña (1882) se publica oficialmente como el primer ejemplo de una doctrina militar unificada en España. Almirante será además un escritor mordaz, que no dudará en señalar los vicios del ejército en su época, lo que le valdrá no pocas críticas ${ }^{26}$.

Mención especial merece también Carlos Banús, un pensador muy original, y con influencia en Europa ${ }^{27}$ que se encuadrará entre los profetas de la guerra total que precedieron a la Primera Guerra Mundial.

Mientras España trata de gestionar su decadencia a lo largo del siglo XIX, al otro lado del Atlántico las jóvenes repúblicas surgidas de la descolonización tratan de consolidarse como Estados. La independencia comienza en casi toda Iberoamérica con la guerra y el papel de los militares es allí esencial. La mayor parte de los libertadores son de hecho oficiales del ejército español, que se convierten en líderes de los diferentes movimientos de emancipación. Muchos de los libertadores, especialmente Bolívar, tienen una obra literaria considerable, aunque la mayor parte de ellas son manifiestos, proclamas, textos legislativos,

\footnotetext{
${ }^{24}$ Ibid. p.44 y 166.

${ }^{25}$ Ibid. p. 44.

${ }^{26}$ Ibid. p. 37.

${ }^{27}$ Ibid. p. 271.
}

Araucaria. Revista Iberoamericana de Filosofia, Política, Humanidades y Relaciones Internacionales, año $22, \mathrm{n}^{\circ} 44$. Segundo semestre de 2020. Pp. 495-519. ISSN 1575-6823 e-ISSN 2340-2199 https://dx.doi.org/10.12795/araucaria.2020.i44.23 
o bien obras de naturaleza política. El pensamiento estratégico militar está, en general, ausente y no se recuperará hasta que los historiadores comiencen a analizar las guerras de independencia.

El general y presidente argentino Bartolomé Mitre escribirá ya en la segunda mitad del siglo Historia de Belgrano o de la independencia argentina e Historia de San Martín y de la emancipación americana, textos que han pasado a formar parte de la historia oficial de la nación argentina ${ }^{28}$ y que cubrían las operaciones militares que comenzaron desde el Cono Sur de América del Sur. En México, Carlos María de Bustamante analizará las campañas tanto de los rebeldes como de los realistas en, por ejemplo, Historia militar del general don José María Morelos o Campañas del general Félix María Calleja ${ }^{29}$. En Venezuela, el general José de Austria escribe "Bosquejo de historia militar de Venezuela en la guerra de independencia" que, si bien es esencialmente una obra de alabanza a Bolívar, tiene el mérito de ser también una historia bastante detallada de sus campañas militares ${ }^{30}$.

Iberoamérica se vio sacudida por numerosos conflictos civiles e interestatales en el siglo XIX que, en general, retrasaron la consolidación plena de las nuevas naciones, así como de sus ejércitos nacionales. Algunos fueron especialmente sangrientos, como la guerra de la Triple Alianza (1864-1870) que casi aniquiló a la población de Paraguay; otras supusieron cambios geopolíticos importantes, como la guerra del Pacífico (1879-1884), que cerró el acceso de Bolivia al mar y consolidó a Chile como potencia militar dominante en la costa occidental de América del Sur. En algunos casos, las naciones iberoamericanas tuvieron que hacer frente al intervencionismo, tanto de Estados Unidos (guerra contra México en 1846-1848) como de potencias europeas (Francia en la expedición a México de 1861 o España en la intervención en la costa del Pacífico en 1866). No obstante, en lugar de servirse de estas experiencias bélicas para desarrollar modelos militares nacionales, los Ejércitos iberoamericanos recurrieron a solicitar la presencia de expertos militares europeos.

A lo largo del siglo XIX, la tendencia en Iberoamérica va a ser similar a la de Europa con la influencia de Prusia primero, y Alemania después, desplazando progresivamente a Francia como modelo militar. A finales del siglo XIX, la influencia militar alemana, a través de asesores, profesores y técnicos era muy notable sobre todo en Chile, pero también en Bolivia, Argentina y Paraguay ${ }^{31}$.

${ }^{28}$ Gonzalo García Garro, "La historia oficial, liberal o mitrista". Noticias entre ríos, 28 octubre 2017. Disponible en: https://www.noticiasentrerios.net.ar/2017/10/la-historia-oficial-liberal-omitrista.html Consultado el 23 de marzo de 2020.

${ }^{29}$ Morelos fue uno de los líderes de la primera revuelta en México, precisamente sofocada por Félix María Calleja, primero jefe militar realista y después virrey de Nueva España.

${ }^{30}$ Germán Guía Caripe, "Historiografía e Historia Militar: El Bosquejo de Historia Militar de Venezuela en la Guerra de Independencia del general de división José de Austria”, Revista Tiempo y Espacio, n. 53, Caracas, junio 2010. Disponible en: http://ve.scielo.org/scielo.php?script=sci_arttext $\underline{\text { \&pid }=\mathrm{S} 1315-94962010000100006}$ Consultado el 23 de marzo de 2020.

${ }^{31}$ Frederick, M. Nunn, "European military influence in South America: the origins and nature of professional militarism in Argentina, Brazil, Chile and Peru, 1890-1940", Anuario de Historia de 
Perú se mantenía más próximo a Francia y, en México, alemanes y franceses pugnaban por convertirse en asesores y mentores del Ejército mexicano ${ }^{32}$. Ese mismo fenómeno ocurrió en otros países iberoamericanos, como Argentina o Brasil, hasta la Segunda Guerra Mundial, alternándose periodos "francófilos" o "germanófilos", o dividiéndose los cuerpos de oficiales en simpatizantes de uno u otro modelo ${ }^{33}$.

\section{El siglo $\mathrm{XX}$}

El siglo XX comienza para España con la sombra del Desastre del 98. La pérdida de las últimas colonias, tras una derrota rápida y completa, socava profundamente el prestigio de la nación. Las Fuerzas Armadas, que hasta la Restauración tenían buena imagen ante la población, la pierden por una acumulación de sucesos desafortunados. El servicio militar obligatorio, instaurado progresivamente a lo largo del siglo XIX, fue siempre impopular por su escasa equidad, las duras condiciones en las que se prestaba y el alto coste en bajas en las guerras coloniales. Las guerras en el Marruecos español, con desastres como el Barranco del Lobo (1909) y, sobre todo, Annual (1921), agudizarán la separación progresiva entre los ejércitos y una gran parte de la sociedad, provocarán graves crisis políticas y convertirán la incompetencia militar en un tópico popular.

En este ambiente tan adverso se produce, sin embargo, un cierto renacimiento cultural con una importante producción literaria militar. Las experiencias de la Primera Guerra Mundial, la guerra del Rif y las propuestas regeneracionistas en el seno del Ejército serán los temas más frecuentemente analizados por los tratadistas militares de esa época. Como ocurrió en Iberoamérica, la oficialidad se divide también en germanófilos y francófilos, aunque a ellos habría que añadir otro grupo numeroso de "africanistas" que se centran en justificar y extraer lecciones de la colonización y siguen normalmente el modelo francés de líderes militares como Bugeaud o Lyautey.

Cabe mencionar entre los regeneracionistas al general Ricardo Burguete, a quien se llega a considerar representante militar en la Generación del 98, y que escribe entre otras obras El problema militar (1905) y La guerra y el hombre (1911). Burguete continúa la línea iniciada por Carlos Banús, basada en la escuela militar prusiano-alemana, centrada en la guerra industrial que requería una movilización total de recursos económicos y humanos. Burguete mantendrá, no obstante, la línea tradicional española de dedicar una gran atención a los valores psicológicos

América Latina, volumen 12, 01 diciembre 1975, p.233. Disponible en: https://www.degruyter.com/ view/journals/jbla/12/1/article-p230.xml Consultado el 25 de marzo de 2020.

32 Warren Schiff, "German military penetration into Mexico during the late Diaz period", The Hispanic American Historical Review Vol. 39, No. 4, (Nov., 1959), p. 568. Disponible en: https:// www.jstor.org/stable/2510381?seq=1 Consultado el 25 de marzo de 2020.

${ }^{33}$ Frederick, M. Nunn, pp. 237-238.

Araucaria. Revista Iberoamericana de Filosofí, Política, Humanidades y Relaciones Internacionales, año 22, $\mathrm{n}^{\circ} 44$. Segundo semestre de 2020. Pp. 495-519. ISSN 1575-6823 e-ISSN 2340-2199 https://dx.doi.org/10.12795/araucaria.2020.i44.23 
y morales ${ }^{34}$. Entre los africanistas destaca el general Dámaso Berenguer y su La guerra de Marruecos, obra muy inspirada en el modelo colonial francés que consideraba la colonización como una obligación civilizadora y una escuela de mandos. Alto comisario de España en Marruecos durante el Desastre de Annual (1921) escribirá también Operaciones en el Rif y Yebala como defensa contra las acusaciones que se le hicieron por su responsabilidad en el desastre ${ }^{35}$.

En 1924, se publica en España la Doctrina para el Empleo de las Armas y los Servicios, primera doctrina militar realmente oficial tras el antecedente del Reglamento para el servicio en campaña de 1882, escrito por Almirante. La doctrina de 1924 muestra la tendencia del pensamiento militar de la época que se mantendrá durante casi todo el siglo XX: la importación de modelos extranjeros. La neutralidad de España en la Primera Guerra Mundial llevó a los tratadistas españoles a adoptar las ideas de sus homólogos en otros países. Curiosamente, las propias experiencias españolas tuvieron poca influencia, e incluso las duras, pero sin duda útiles lecciones aprendidas del Desastre de Annual, se despreciaron explícitamente en la propia doctrina.

La difusión del pensamiento militar extranjero, y los intentos por adaptarlo a las peculiaridades y necesidades de las fuerzas armadas españolas, serán la tarea principal de los pensadores militares de la época. En este sentido destaca la iniciativa de los entonces capitanes Vicente Rojo y Emilio Alamán, publicando la Colección Bibliográfica Militar a partir de 1928. En ella se tradujeron y publicaron algunas de las firmas europeas más prestigiosas en el campo del pensamiento militar $^{36 .}$

Precisamente, Vicente Rojo, que durante la Guerra Civil llegó a ser jefe de Estado Mayor del Ejército de la República, fue el tratadista español más notable de la época. Rojo, profesor durante 10 años en la Academia de Infantería de Toledo, era un seguidor del pensamiento militar francés contemporáneo, centrado en el mantenimiento de la iniciativa y la ofensiva. Su experiencia en la Guerra Civil, en la que intentó aplicar sus teorías con escaso éxito, le hizo más escéptico y le hizo girar hacia posiciones más políticas centradas en la lucha contra el imperialismo y la resistencia popular. Sus obras principales fueron escritas durante su exilio en Bolivia, destacando los Elementos del arte de la guerra, un completo tratado sobre táctica y estrategia que constituye una de las obras principales del pensamiento militar español de este siglo ${ }^{37}$.

\footnotetext{
34 Biblioteca Nacional de España, "Escritores en la BNE. Ricardo Burguete (1871-1937)". Disponible en: http://escritores.bne.es/web/authors/ricardo-burguete-1871-1937/ Consultado el 26 de marzo de 2020.

35 Maria Rosa de Madariaga, "Los estudios sobre el Protectorado Español en perspectiva" en López García, Bernabé y Hernando de Larramendi, Miguel, Historia y memoria de las relaciones hispano-marroquies, Ediciones del Oriente y del Mediterráneo, Madrid, 2007, p.27

${ }^{36}$ Se publicaron 95 números entre 1928 y 1936, que incluyeron la traducción de 29 obras militares extranjeras (Aspizúa, Bernabéu \& Molina, "La Colección Bibliográfica Militar", Revista de Estudios Políticos, número 64, abril-junio 1989, pp. 299-319).

${ }^{37}$ Vicente Rojo Lluch, Elementos del Arte de la Guerra, Publicaciones de Defensa, Madrid, 2010.
} 
Pese a que la Guerra Civil española fue utilizada como campo de experimentación para nuevas tácticas y materiales, que luego se utilizaron en la Segunda Guerra Mundial, su impacto en el pensamiento militar español fue muy limitado. Durante el régimen de Franco, la actividad intelectual en las Fuerzas Armadas decayó sensiblemente, aunque algunos tratadistas mantuvieron encendida la llama del pensamiento militar.

Un grupo de ellos se dedicó a la historia militar de la Guerra Civil, obviamente desde el punto de vista de los vencedores. Destacan, entre ellos, Ramón Salas Larrazábal y José Manuel Martínez Bande, que realizaron una labor de investigación y recopilación de fuentes que ha servido de base para posteriores historiadores civiles. También aparece una escuela de pensamiento militar centrado, como era tradicional en España, en los valores morales y la filosofía de la guerra con un claro componente de humanismo cristiano. El general Miguel Alonso Baquer, con una extensa obra, es probablemente su representante más conocido.

En cuanto al pensamiento centrado en la estrategia militar y el arte operacional, la lista de autores destacados es más reducida, aunque destaca el teniente general Carlos Martínez Campos. En su obra recoge las experiencias de la Segunda Guerra Mundial y las mezcla con la amenaza de guerra nuclear propia de la Guerra Fría. El resultado es una curiosa continuación de la escuela de pensadores estratégicos de la guerra total, iniciada por Banús y Burguete. La guerra anunciada por Martínez Campos tiene mucho de apocalipsis industrial con retaguardias devastadas por ataques aéreos y armas nucleares.

Mientras, en España, el pensamiento militar se centra en tratar de adaptar los modelos extranjeros, especialmente los que aparecen en las guerras mundiales, en Iberoamérica comienzan a asentarse los centros de pensamiento que dará origen a un pensamiento militar autóctono. Chile se convierte en uno de los referentes iberoamericanos en organización militar, basándose en un modelo netamente alemán. El general Emil Körner Henze, de nacionalidad alemana, pero que pasó gran parte de su carrera militar al servicio del Ejército chileno, fue uno de los principales promotores de su modernización. Körner fue un personaje curioso, pues, siendo alemán, tomó partido en la Guerra Civil chilena de 1891 por la facción que apoyaba al parlamento frente al presidente, y su labor fue lo bastante importante como para que fuese nombrado jefe de Estado Mayor del Ejército a su finalización ${ }^{38}$.

Aunque Chile exportó un número importante de instructores y profesores a otros países, pronto se encontró con la competición de Argentina y Brasil como referentes militares en Iberoamérica. De hecho, a principios del siglo XX se desarrolló una carrera de armamentos entre Brasil, Argentina y Chile que se

\footnotetext{
38 José Javier Díaz Sánchez-Pacheco, "Pensadores militares chilenos y ecuatorianos del siglo XX y su influencia en la Región Andina" en Pensamiento y pensadores militares iberoamericanos del siglo XX y su influencia en la Comunidad Iberoamericana, dirigida por Agustín Quesada Gómez, Ministerio de Defensa, Madrid, 2003. pp. 231-232.
} 
reflejó sobre todo en la construcción naval. El proyecto brasileño de dotar a su marina de guerra de tres acorazados tipo dreadnought provocó una reacción en sus vecinos que comenzaron programas de construcción similares ${ }^{39}$. La tensión geopolítica se mantendrá entre las tres naciones, por décadas, aunque finalmente no se traducirá en un conflicto bélico. Sin embargo, las disputas fronterizas entre Bolivia y Paraguay sí que llevaron, en 1932, a la guerra del Chaco, el mayor enfrentamiento bélico en Iberoamérica en la primera mitad del siglo XX.

La tensión y los conflictos locales, así como las experiencias importadas de la Primera Guerra Mundial, provocarán un renacimiento del interés por el pensamiento estratégico en la región. La aparición de la geopolítica como una nueva disciplina, especializada en analizar el equilibrio de poder entre potencias, motivará a muchos oficiales iberoamericanos para abordar estudios geopolíticas. En esta época destaca una iniciativa tomada en Argentina por el teniente coronel Martínez Pita: la creación de una Biblioteca del Oficial consistente en una colección de publicaciones de pensamiento militar autóctono y extranjero ${ }^{40}$ que ha sobrevivido hasta nuestros días y se ha convertido en el mayor referente bibliográfico del pensamiento militar en español en el mundo.

Pero si hay que destacar dos tendencias en la primera mitad del siglo XX en las instituciones militares iberoamericanas son, por un lado, la continuidad del intervencionismo militar en política; y, por otra, la creciente influencia de Estados Unidos como principal referencia militar del continente, reemplazando progresivamente la influencia europea.

Como ocurrió en España en el siglo XIX, la intervención militar en política en Iberoamérica seguirá diversas tendencias, entre las que pueden destacarse dos principales: por un lado, los conservadores, normalmente defensores de los intereses de las oligarquías locales; y, por otro, los populistas, que se acercarán al pueblo como base para una transformación social orientada hacia una combinación de socialismo y nacionalismo. Todos los países iberoamericanos experimentarán gobiernos militares conservadores, pero el impacto histórico y mediático del populismo será considerablemente mayor.

El general y político argentino Juan Domingo Perón se convertirá en el prototipo del militar populista con una influencia que llega hasta nuestros días. Perón fue también un notable escritor militar con obras que comienzan con la historia militar de Argentina y van evolucionando hacia la teoría política y la geopolítica $^{41}$.

39 Seward W.Livermore, "Battleship diplomacy in South America (1905-1925)", The Journal of Modern History Vol. 16, No. 1 (Mar., 1944), pp. 31-48. Disponible en: https://www.jstor.org/ stable/1870986?read-now=1\&seq=1\#page scan tab contents Consultado el 26 de marzo de 2020.

${ }^{40}$ Francisco Javier Martín García, "Pensadores Militares del siglo XX de Argentina, Paraguay y Uruguay, y su influencia en la región" en Pensamiento y pensadores militares iberoamericanos del siglo XX y su influencia en la Comunidad Iberoamericana, dirigida por Agustín Quesada Gómez, Ministerio de Defensa, Madrid, 2003, pp. 181-183.

${ }^{41}$ Cabría destacar sus Apuntes de historia militar de 1932. Disponible en: http://www.labaldrich. com.ar/wp-content/uploads/2019/04/Apuntes\%20de\%20Historia\%20Militar\%20-\%20Juan\%20

Araucaria. Revista Iberoamericana de Filosofia, Política, Humanidades y Relaciones Internacionales, año 22 , $\mathrm{n}^{\circ} 44$. Segundo semestre de 2020. Pp. 495-519. ISSN 1575-6823 e-ISSN 2340-2199 https://dx.doi.org/10.12795/araucaria.2020.i44.23 
La influencia norteamericana aumentará progresivamente en Iberoamérica durante el siglo XIX, especialmente en México y el Caribe. El interés por comunicar el océano Pacífico y el Atlántico a través de un canal en Panamá, llevó a que Washington apoyase la independencia de este país de Colombia, lo que provocó la Guerra de los Mil Días (1899-1902), que dejó al Estado colombiano devastado. Hasta bien entrados los años 30, Estados Unidos continuó interviniendo en Centroamérica y el Caribe (Haití, República Dominicana, Nicaragua, Veracruz). Sin embargo, fue la Segunda Guerra Mundial la que convirtió a Estados Unidos en el referente militar prioritario en toda Iberoamérica. Durante la Guerra Fría, la creación de la Escuela de las Américas en Panamá como centro de adiestramiento para militares latinoamericanos en la lucha contra guerrillas e insurgencias tuvo una gran influencia en la evolución doctrinal de los ejércitos de la región ${ }^{42}$.

Regresando a España, el final del régimen de Franco trajo consigo un renovado interés por cuestiones estratégicas y de seguridad, ya que España comenzó a integrarse en las organizaciones europeas con responsabilidades en seguridad y defensa. Los tradicionales estudios estratégicos se fueron transformando paulatinamente en estudios de seguridad y el pensamiento militar comenzó a integrarse dentro de esa corriente. Ya en los últimos años de dictadura se tomaron algunas decisiones que facilitaron esa transición.

En 1964 se funda el Centro de Estudios de la Defensa Nacional (CESEDEN), pensado para impulsar los estudios estratégicos y acercar fuerzas armadas y sociedad civil. En 1970, se crea el Instituto Español de Estudios Estratégicos que pronto orienta su actividad a la colaboración con universidades y centros de pensamiento.

En esos años destaca la figura del teniente general Manuel Díez-Alegría, director del CESEDEN y después jefe del Alto Estado Mayor, que tuvo una influencia modernizadora sobre la institución militar, preparando la transición política que llegaría tras la muerte de Franco. Díez-Alegría escribirá Ejército y sociedad (1972), que será una referencia intelectual para el proceso modernizador que se iniciaría solo unos años más tarde.

En los años 90 se estrechará la relación entre centros militares de enseñanza y universidades a través de la firma de convenios y en 1997 se crea el Instituto Universitario Gutiérrez Mellado, una institución fruto de la colaboración militar y civil para impartir títulos de posgrado en estudios de seguridad y defensa. Como ocurrió antes en otros países europeos, o en Estados Unidos, el pensamiento militar fue fundiéndose en los estudios académicos de seguridad y defensa, en los que las universidades fueron asumiendo el liderazgo. Con el cambio de siglo y milenio esta integración se acentuó y, aunque los estudios

Domingo\%20Per\%C3\%B3n.PDF y Conducción política, de 1971. Disponible en: https://web.archive. org/web/20190704210255/http://www.jdperon.gov.ar/institucional/cuadernos/Cuadernillo11.pdf

${ }^{42}$ Pensamiento y pensadores militares iberoamericanos del siglo XX y su influencia en la Comunidad Iberoamericana, dirigida por Agustín Quesada Gómez, Ministerio de Defensa, Madrid, 2003, p. 365.

Araucaria. Revista Iberoamericana de Filosofia, Política, Humanidades y Relaciones Internacionales, año $22, \mathrm{n}^{\circ} 44$. Segundo semestre de 2020. Pp. 495-519. ISSN 1575-6823 e-ISSN 2340-2199 https://dx.doi.org/10.12795/araucaria.2020.i44.23 
en seguridad y defensa son todavía un recién llegado en el mundo académico español, existe ya una base de expertos, enseñanzas y titulaciones que permiten augurar un futuro brillante para el pensamiento estratégico en España.

En Iberoamérica, durante los años 60 y en el marco de la Guerra Fría, se extendieron los conflictos civiles de naturaleza revolucionaria, tomando como modelo la revolución cubana. Paradójicamente, algunos de los textos más universalmente difundidos del pensamiento estratégico iberoamericano proceden de líderes guerrilleros e insurgentes. Destaca, en primer lugar, La guerra de guerrillas de Ernesto Che Guevara, en la que el revolucionario argentino y símbolo de la revolución cubana expresaba su preferencia por la guerrilla como el método más simple y eficaz para derrocar a un régimen autoritario, alejándose de las concepciones de Lenin o Mao sobre una compleja sucesión de fases en la lucha revolucionaria. No obstante, pese a la fama del Che, el libro que mayor influencia y aplicación práctica ha tenido ha sido El minimanual de la guerrilla urbana de Carlos Marighella, escrito en 1969, que aún sigue sirviendo de inspiración no solo para grupos revolucionarios, sino para bandas criminales y grupos terroristas islámicos.

La ola democratizadora de los años 80 y la finalización de numerosos conflictos civiles en los años 90, después de la Guerra Fría, redujeron sensiblemente la implicación de los Ejércitos iberoamericanos en la política de sus países, lo que les permitió centrarse en su profesionalización y modernización. Como en España, los estudios estratégicos y de seguridad se extendieron a las universidades y centros de enseñanza, integrándose el pensamiento militar en la corriente general de los estudios de seguridad. La influencia norteamericana sigue presente, pero también han surgido muchas iniciativas de cooperación e intercambio entre los ejércitos de Iberoamérica, desde el Consejo de Defensa Suramericano, la Conferencia de Ministros de Defensa o el liderazgo, por fuerzas armadas latinoamericanas de la misión de paz de Naciones Unidas en Haití (MINUSTAH) ${ }^{43}$.

\section{Conclusiones}

El pensamiento estratégico militar en España e Iberoamérica se ha enfrentado a considerables dificultades históricas. En España, la más evidente fue la decadencia nacional que coincidió precisamente con el momento de mayor auge del pensamiento militar en Europa. En Iberoamérica, el turbulento proceso

43 Javier Ponce Cevallos, "Iniciativas regionales de cooperación en Defensa" en Sistemas de enseñanza militar y de educación para la Defensa en Iberoamérica, Instituto Universitario Gutierrez Mellado, Madrid 2010, pp.25-26. Disponible en: https://iugm.es/wp-content/uploads/2016/07/ SISTEMAS DE ENSENANZA MILITAR.pdf Consultado el 28 de marzo de 2020. 
de consolidación de las naciones surgidas de las posesiones españolas en América retrasó la aparición de un pensamiento estratégico militar autóctono y llevó a la adopción de modelos europeos.

A ambos lados del Atlántico, el intervencionismo militar en política que, de manera irregular, se prolongó hasta la segunda mitad del siglo XX dificultó la profesionalización plena de las fuerzas armadas y la aparición de escuelas de tratadistas y pensadores centrados en los aspectos técnicos de la seguridad y la defensa.

Pese a todas las dificultades ha habido también momentos brillantes. En el siglo XVI y parte del siglo XVII, el pensamiento militar español estaba en la vanguardia de Europa. Los cronistas e historiadores que acompañaban a ejércitos y expediciones son todavía hoy una referencia esencial y no solo por el interés histórico de lo que describen, sino por el modelo estratégico que presentan. En disciplinas asociadas, como el derecho de la guerra y el derecho humanitario, los tratadistas españoles de la época fueron auténticos pioneros, mientras que los hombres de armas que empuñaron la pluma sentaron las bases de un modelo militar que siempre ha concedido una importancia esencial a los valores morales.

Esa época brillante ha quedado un tanto en el olvido, marginada por el gran desarrollo del pensamiento estratégico militar en los siglos XIX y XX, cuando España se encontraba no solo en decadencia, sino en una larga y dolorosa crisis interna. No es que hayan faltado excelentes autores en los dos últimos siglos, pero su labor ha quedado oscurecida porque, sin el apoyo de unas instituciones militares y académicas centradas en otros problemas más acuciantes, su labor tuvo que limitarse normalmente a importar y analizar ideas nacidas en el extranjero.

Algo similar ocurrió en Iberoamérica donde, hasta la segunda mitad del siglo $\mathrm{XX}$, muchos ejércitos nacionales seguían bajo la tutela de asesores y profesores militares europeos primero y norteamericanos después. Aunque surgieron excelentes autores locales, especialmente en el campo de la historia militar, tuvieron que superar, como sus homólogos españoles, las limitaciones e inercias de unas instituciones militares poco proclives a la investigación académica y de unas instituciones académicas poco interesadas en lo militar y lo estratégico.

La llegada del siglo XXI ha traído consigo el fin del intervencionismo militar, grandes avances en la profesionalización de los ejércitos y que la colaboración militar multinacional se convierta en habitual. Además, los estudios de seguridad y defensa han experimentado un notable auge a ambos lados del Atlántico y la mayoría de los centros universitarios ofrecen hoy programas de titulación en estas materias. En este contexto, las oportunidades para un renacimiento del pensamiento estratégico militar tanto en España como en Iberoamérica se multiplican, aunque el pensamiento militar como tal se integra progresivamente en una corriente más general, que incluye a cada vez 
más académicos, y en la que los estudios estratégicos se convierten en una rama de los estudios de seguridad y defensa.

El desarrollo de una escuela de pensamiento estratégico que utilice el español y el portugués como lenguas de trabajo es una aspiración tradicional tanto en la península Ibérica como en América Central y del Sur. Con ello se abriría una vía nueva en un campo tradicionalmente dominado por expertos anglosajones y se sentarían las bases para abordar problemas de seguridad que son comunes en ambas orillas del Atlántico. Esperemos que este nuevo siglo y milenio sea testigo de cómo el pensamiento estratégico español e iberoamericano recupera el terreno perdido en los dos últimos siglos y ocupa el puesto que por justicia histórica le corresponde. 


\section{Referencias bibliográficas:}

Alemany, Rafael, "Dimensión humanística de una obra menor de Alfonso de Palencia: el Tratado de la perfección del triunfo militar (1459)", Anales de Literatura Española. Núm. 1, 1982. Disponible en: http://www. cervantesvirtual.com/nd/ark:/59851/bmcdv1x 8 Consultado el 18 de marzo de 2020.

Alfonso X, Las Siete Partidas de Alfonso X el Sabio, PensamientoPenal. Disponible en: http://ficus.pntic.mec.es/jals0026/documentos/ textos/7partidas.pdf Consultado el 17 de marzo de 2020.

Apuntes de historia militar de 1932. Disponible en: http://www.labaldrich. com.ar/wp-content/uploads/2019/04/Apuntes $\% 20 \mathrm{de} \% 20$ Historia $\% 20$ Militar\%20-\%20Juan\%20Domingo\%20Per\%C3\%B3n.PDF

Asenjo de la Hoz, Álvaro, "La imprenta de Marte: la guerra en los libros de la Edad Moderna", Documentos de trabajo UCM, Biblioteca Histórica; Madrid 2016/08. Disponible en: https://eprints.ucm.es/38530/1/DT201608.pdf Consultado el 21 de marzo de 2020.

Berasategui, Blanca, "El Lazarillo no es anónimo", elcultural, 5 de marzo de 2010. Disponible en: https://elcultural.com/El-Lazarillo-no-es-anonimo Consultado el 21 de marzo de 2020.

Bernabéu \& Molina Aspizúa, “La Colección Bibliográfica Militar”, Revista de Estudios Políticos, número 64, abril-junio 1989.

Biblioteca Nacional de España, "Escritores en la BNE. Ricardo Burguete (1871-1937)". Disponible en: http://escritores.bne.es/web/authors/ricardoburguete-1871-1937/ Consultado el 26 de marzo de 2020.

Conducción política, de 1971. Disponible en: https://web.archive.org/ web/20190704210255/http://www.jdperon.gov.ar/institucional/ cuadernos/Cuadernillo11.pdf.

de Isaba, Marcos, Cuerpo enfermo de la milicia española, Publicaciones de Defensa, Madrid, 1991.

de Madariaga, Maria Rosa, "Los estudios sobre el Protectorado Español en perspectiva” en López García, Bernabé y Hernando de Larramendi, Miguel, Historia y memoria de las relaciones hispano-marroquíes, Ediciones del Oriente y del Mediterráneo, Madrid, 2007.

de Navia y Osorio, Álvaro, Reflexiones Militares, Secretaría General Técnica del Ministerio de Defensa, Madrid, 2004.

de Salazar, Diego, Tratado de Re Militari, Bruselas, 1590. Disponible en: $\underline{\text { http:// }}$ www.bibliotecavirtualdeandalucia.es/catalogo/es/catalogo imagenes/ grupo.cmd?path=151464 Consultado el 18 de marzo de 2020.

Díaz Sánchez-Pacheco, José Javier, "Pensadores militares chilenos y ecuatorianos del siglo XX y su influencia en la Región Andina” 
Fernández García, Pelayo, Las Reflexiones militares del marqués de Santa Cruz de Marcenado y su influencia más allá de las fronteras nacionales, Ministerio de Defensa, Madrid, 2015.

García Garro, Gonzalo, "La historia oficial, liberal o mitrista". Noticias entre ríos, 28 octubre 2017. Disponible en: https://www.noticiasentrerios.net. ar/2017/10/la-historia-oficial-liberal-o-mitrista.html Consultado el 23 de marzo de 2020.

Guía Caripe, Germán, "Historiografía e Historia Militar: El Bosquejo de Historia Militar de Venezuela en la Guerra de Independencia del general de división José de Austria”. Revista Tiempo y Espacio, n. 53, Caracas, junio 2010. Disponible en: http://ve.scielo.org/scielo.php?script=sci artte xt\&pid=S1315-94962010000100006 Consultado el 23 de marzo de 2020.

Hurtado de Mendoza, Diego, Guerra de Granada, Cervantes virtual. Disponible en: http://www.cervantesvirtual.com/obra-visor/guerra-degranada-hecha-por-el-rey-de-espana-don-felipe-ii-contra-los-moriscosde-aquel-reino-sus-rebeldes-historia-escrita-en-cuatro-libros--0/html/ fee8dfa0-82b1-11df-acc7-002185ce6064_2.htm Consultado el 21 de marzo de 2020.

Lechuga, Cristóbal, Discurso del capitan Cristoual Lechuga: en que trata de la artilleria, y de todo lo necessario à ella, con un tratado de fortificacion $y$ otros aduertimentos..., Milán 1611. Disponible en: http://www. cervantesvirtual.com/obra/discurso-del-capitan-cristoual-lechuga--enque-trata-de-la-artilleria-y-de-todo-lo-necessario-a-ella-con-un-tratadode-fortificacion-y-otros-aduertimentos/ Consultado el 20 de marzo de 2020.

Livermore, Seward W., "Battleship diplomacy in South America (19051925)", The Journal of Modern History, Vol. 16, No. 1 (Mar, 1944), pp. 31-48. Disponible en: https://www.jstor.org/stable/1870986?readnow $=1 \&$ seq $=1 \#$ page scan tab contents Consultado el 26 de marzo de 2020.

Martín García, Francisco Javier, "Pensadores Militares del siglo XX de Argentina, Paraguay y Uruguay, y su influencia en la región"

Martínez Laínez, Fernando, Una pica en Flandes, La epopeya del Camino Español, EDAF, Madrid, 2007. p. 182.

Napier, W., History of the War in the Peninsula and in the South of France from the Year 1807 to the Year 1814, Londres, 1828-1840.

Nunn, Frederick M., "European military influence in South America: the origins and nature of professional militarism in Argentina, Brazil, Chile and Peru, 1890-1940", Anuario de Historia de América Latina, volumen 12, 01 diciembre 1975, p. 233. Disponible en: https://www.degruyter.com/view/ journals/jbla/12/1/article-p230.xml Consultado el 25 de marzo de 2020. 
Oman, Charles, A History of the Peninsular War Vol II, Oxford Clarendon Press, 1903.

Palmer, R.R., "Federico el Grande, Guibert, Bulow. De las guerras dinásticas a las nacionales" en Peter Paret, Creadores de la Estrategia Moderna, Ministerio de Defensa, Madrid, 1992.

Pérez Frías, Pedro Luis, "El Ejército de Carlos III", Revista Péndulo, n 18, 2007. Disponible en: https://dialnet.unirioja.es/servlet/autor?codigo $=819236$ Consultado el 22 de marzo de 2020.

Pérez Llamazares, Julio, Estudio crítico y literario de las obras de San Isidoro, Arzobispo de Sevilla, y la influencia de las mismas en la reforma de la disciplina y formación del clero, Editorial Crónica de León, León, 1925, p.31. Disponible en: https://bibliotecadigital.jcyl.es/es/consulta/registro. cmd? $\mathrm{id}=5253$ Consultado el 16 de marzo de 2020.

Pinto Cebrián, Guillermo, Ejército e historia. El pensamiento profesional militar español a través de la literatura castrense decimonónica, Ministerio de Defensa, Madrid, 2013.

Ponce Cevallos, Javier, "Iniciativas regionales de cooperación en Defensa" en Sistemas de enseñanza militar y de educación para la Defensa en Iberoamérica, Instituto Universitario Gutiérrez Mellado, Madrid 2010, pp. 25-26. Disponible en: https://iugm.es/wp-content/uploads/2016/07/ SISTEMAS_DE_ENSENANZA_MILITAR.pdf Consultado el 28 de marzo de 2020.

Quesada Gómez, Agustín (director) Pensamiento y pensadores militares iberoamericanos del siglo XX y su influencia en la Comunidad Iberoamericana, dirigida por Agustín Quesada Gómez, Ministerio de Defensa, Madrid, 2003.

Rojo Lluch, Vicente, Elementos del arte de la guerra, Publicaciones de Defensa, Madrid, 2010.

Romero Galván, José Rubén, "Los cronistas indígenas en el siglo XVII", Instituto de Investigaciones Históricas (UNAM) 2002. Disponible en: http://www.elem.mx/estgrp/datos/158 Consultado el 21 de marzo de 2020.

Ruiza, M., Fernández, T. y Tamaro, E., "Biografía de Garcilaso El Inca". En Biografias y Vidas. La enciclopedia biográfica en línea, Barcelona, 2004. Disponible en: https:/www.biografiasyvidas.com/biografia/g/ garcilaso el inca.htm Consultado el 21 de marzo de 2020.

Schiff, Warren, "German military penetration into Mexico during the late Diaz period", The Hispanic American Historical Review Vol. 39, No. 4, (Nov., 1959), p. 568. Disponible en: https://www.jstor.org/stable/2510381?seq=1 Consultado el 25 de marzo de 2020. 
